\title{
Vivências de mães de crianças usuárias de implante coclear: percurso entre assistência à saúde e escolarização
}

Experiences of mothers of children using cochlear implants: path between health care and schooling

Experiencias de madres de niños con implantes cocleares: camino entre la asistencia sanitaria y la escolarización

\section{Resumo}

Objetivo: Compreender as vivências de mães de crianças usuárias de implante coclear quanto ao percurso para a assistência em saúde e escolarização do(a) filho(a). Metodologia: Estudo qualitativo, que utilizou o referencial teórico histórico-cultural de Vygotski, através da narrativa de vida e a unidade de análise a vivência. Foi realizado em 2018, com quatro mães de filhos usuários de implante coclear em acompanhamento fonoaudiológico na clínica da Universidade Estadual de Ciências da Saúde de Alagoas, na cidade de Maceió, Alagoas. Os dados foram produzidos a partir das entrevistas narrativas com as mães e organizados em 4 unidades temáticas. Resultados: As vivências das mães evidenciaram a mobilização e persistência que cada uma necessitou para conseguir a realização do implante coclear em seus filhos, bem como, os danos no desenvolvimento das crianças decorrentes da realização tardia do procedimento e as dificuldades no âmbito da saúde e na inclusão escolar. Considerações finais: A partir de suas vivências foi possível compreender os aspectos que potencializaram e/ou fragilizaram o desenvolvimento das crianças, tais como o despreparo dos profissionais de saúde no repasse de informações sobre o implante coclear para as famílias durante os primeiros meses de vida das crianças. As dificuldades no processo de escolarização também foram abordadas, estas envolveram a inexperiência dos educadores e a ausência de estratégias voltadas às práticas de alfabetização dessas crianças. Reforçase a necessidade da criação de redes de apoio para mães e suas crianças com implante coclear, proporcionando-lhes acolhimento no enfrentamento das dificuldades ao longo da vida e sua inclusão na sociedade.

Palavras-chave: Implante coclear; Narrativa pessoal; Relações mãe-filho. 


\begin{abstract}
Objective: To understand the experiences of mothers of children using cochlear implants as to the path to health care and schooling for their children. Methodology: Qualitative study, which used the cultural-historical theoretical framework of Vygotski, through the narrative of life and the unit of analysis of the experience. It was carried out in 2018, with four mothers of children who were cochlear implant users in phonoaudiological follow-up in the clinic of the Alagoas State University of Health Sciences, in the city of Maceió, Alagoas. Results: The experiences of the mothers showed the mobilization and persistence that each one needed to get the cochlear implant in their children, as well as the damage to the children's development resulting from the late performance of the procedure and the difficulties in the health sphere and in school inclusion. Final considerations: From their experiences it was possible to understand the aspects that enhanced and/or weakened the children's development, such as the unpreparedness of health professionals in passing on information about cochlear implantation to families during the first months of the children's lives. The difficulties in the schooling process were also addressed, which involved the inexperience of educators and the absence of strategies aimed at the literacy practices of these children. It reinforced the need to create support networks for mothers and their children with cochlear implants, providing them with shelter to face difficulties throughout life and their inclusion in society.
\end{abstract}

Keywords: Cochlear implantation; Personal narrative; Mother-child relations.

\title{
Resumen
}

Objetivo: Conocer las experiencias de las madres de niños que utilizan implantes cocleares en cuanto a la trayectoria de la atención sanitaria y la escolarización de sus hijos. Metodología: Estudio cualitativo, que utilizó el marco teórico cultural-histórico de Vygotski, a través de la narración de la vida y la unidad de análisis de la experiencia. Se realizó en 2018, con cuatro madres de niños usuarios de implantes cocleares en seguimiento fonoaudiológico en la clínica de la Universidad Estatal de Ciencias de la Salud de Alagoas, en la ciudad de Maceió, Alagoas. Resultados: Las experiencias de las madres mostraron la movilización y persistencia que cada una necesitó para conseguir el implante coclear en sus hijos, así como los daños en el desarrollo de los niños derivados de la realización tardía del procedimiento y las dificultades en el ámbito de la salud y la inclusión escolar. Consideraciones finales: A partir de sus experiencias fue posible comprender los aspectos que potenciaron y/o debilitaron el desarrollo de los niños, como la falta de preparación de los profesionales sanitarios a la hora de transmitir la información sobre el implante coclear a las familias durante los primeros meses de vida de los niños. También se abordaron las dificultades en el proceso de escolarización, que implican la inexperiencia de los educadores y la ausencia de estrategias dirigidas a las prácticas de alfabetización de estos niños. Se refuerza la necesidad de crear redes de apoyo para las madres y sus hijos con implantes cocleares, dándoles cobijo para afrontar las dificultades a lo largo de la vida y su inclusión en la sociedad.

Palabras clave: Implantación coclear; Narrativa personal; Relaciones madre-hijo.

\section{Introdução}

O interesse neste estudo decorreu de experiências vivenciadas com uma criança com deficiência auditiva usuária de Implante Coclear (IC) bilateral. O percurso até a realização do IC, envolveu um diagnóstico tardio devido a dificuldade em acesso aos serviços de saúde. As particularidades que envolvem a reabilitação auditiva, oral e o processo de escolarização, despertou indagações que nos levaram a investigar sobre as vivências de outras mães durante esse processo.

$\mathrm{Na}$ literatura são escassos os estudos que apresentam vivências de mães de usuários de IC, especialmente relacionados ao percurso para a realização do implante envolvendo a infância, questionando o trajeto para a realização do IC até o momento final (Yamanada, 2012).

Assim, mostra-se relevante que novas pesquisas busquem contribuir para a qualidade de vida das mães que cuidam de filhos usuários de IC e consequentemente de toda a família, visto que o processo vivencial é ampliado. O conhecimento sobre as experiências vivenciadas, possibilita entender fatores essenciais na fase de desenvolvimento infantil. Nessa direção, o referencial histórico-cultural de Vygotski, possibilita o conhecimento do ser humano de maneira sistêmica, as relações estabelecidas em seu contexto cultural e sua influência no desenvolvimento do indivíduo.

O aprendizado e o desenvolvimento do indivíduo são elementos sócio históricos que, devido às suas raízes sociais, se estruturam nas relações do ser com o meio. Com isso, para compreender essa relação, é necessário analisar seus fundamentos e através da narração se faz possível conhecer os acontecimentos, a percepção e sentimentos do indivíduo, o que possibilita compreender e analisar seus fundamentos históricos e sociais (Vygotski, 1916/1999). 
A motivação para este estudo, com mães de crianças usuárias de IC como participantes, se deu pelo fato de que é imprescindível conhecer a vivência daquela que acompanha a criança em seu processo, pois a sua habilitação/reabilitação depende especialmente de quem cuida (Yamanada, 2012).

Nessa direção, o conhecimento sobre as vivências das mães desde a gestação do seu filho usuário de IC, de forma a conhecer o percurso, o diagnóstico da deficiência auditiva, a realização do IC, o processo para a reabilitação e a trajetória escolar, possibilitam um olhar ampliado para o planejamento do cuidado à família.

Deste modo, este estudo teve como objetivo compreender as vivências de mães de crianças usuárias do Implante Coclear quanto ao percurso relacionado à assistência em saúde e escolarização do(a) filho(a).

\section{Metodologia}

Estudo de abordagem qualitativa, onde, de acordo com Minayo (2012), tem como principal ação o verbo compreender. “A pesquisa qualitativa preocupa-se, com aspectos da realidade que não podem ser quantificados, centrando-se na compreensão e explicação da dinâmica das relações sociais" (Gerhardt \& Silveira, 2009, p. 32). Foi utilizado o método de pesquisa narrativa que é considerada uma representação ou interpretação de mundo, através da qual emergem histórias de vida (Muylaert, Sarubbi Jr, Gallo, Rolim Neto \& Reis, 2014).

Através da entrevista narrativa é possível conhecer a construção histórico social da vida do sujeito de acordo com o que para ele foi marcante e fundamental para o desenvolvimento do seu percurso, além de compreender o contexto social no qual a narrativa se passou e perceber sua influência para o desenvolver das experiências vividas.

A pesquisa foi realizada no município de Maceió - AL, durante os meses de Maio e Junho de 2018 na Clínica Escola de Fonoaudiologia Prof. Jurandir Boia Rocha pertencente à Universidade Estadual de Ciências da Saúde de Alagoas (UNCISAL). A referida clínica exerce atividades de prevenção, orientação e terapia dos distúrbios da comunicação humana que interferem na qualidade de interação social do homem.

Para a inclusão das mães participantes foram elencados os seguintes critérios: 1) filhos em acompanhamento no ambulatório em terapia fonoaudiológica, 2) filhos inseridos no ambiente escolar, 3) filhos em comorbidades além da deficiência auditiva, 4) filhos em uso de IC. Estes dados foram levantados junto ao serviço. O quantitativo de usuários de IC em acompanhamento na clínica perfez o total de 13. Com o auxílio das fonoaudiólogas professoras da clínica e do acesso aos prontuários, criou-se uma planilha contendo o nome da criança, nome dos pais, sexo, idade e número de telefone. Desse total, evidenciou-se que 8 (oito) crianças compreendiam entre 6 e 11 anos de idade, destas, um apresentava paralisia cerebral e outro havia rejeitado o IC e abandonado o uso, dessa forma, 6 atendiam aos critérios de inclusão da pesquisa. Após contato com as mães, apenas apenas 4 (quatro) aceitaram ser participantes do estudo.

As entrevistas foram realizadas durante os meses de Maio e Junho de 2018, na residência das mães e na clínica da UNCISAL de acordo com a conveniência de cada participante, tendo como questão disparadora da entrevista: "Me conte todo seu percurso como mãe de uma criança usuária de implante coclear até os dias atuais". As mães tinham idade entre 25 e 43 anos, com escolaridades diferentes.

De forma a preservar a identidade dos participantes, foi solicitado que cada mãe escolhesse um nome fictício, os quais são utilizados na apresentação das narrativas. São eles: Neide, Cláudia, Maria e Cristiane. A duração das entrevistas com as mães foi de, no mínimo, nove minutos a, no máximo, cinquenta e seis minutos. Após a questão disparadora, realizou-se apenas a escuta atenta e breves anotações, pela pesquisadora, para esclarecimentos. Somente após o término do relato, foram realizadas algumas perguntas para esclarecer acontecimentos. As dúvidas que surgiram após a transcrição das entrevistas e que necessitaram de esclarecimento foram obtidas através de conversas telefônicas com as mães. 
As entrevistas foram transcritas logo após sua realização, com o intuito de evitar qualquer eventualidade que viesse a danificar os arquivos de áudio, além de serem enviados imediatamente para o e-mail da pesquisadora e serem salvos em diversos formatos.

Os dados produzidos foram analisados observando-se as premissas do método em Vygotski. A partir dos acontecimentos da história de vida de cada mãe participante, foi realizada a demarcação dos processos de carga emocional-perejivanie presentes em suas narrativas. As narrativas das mães contribuíram no entendimento e análise dos momentos que transformaram a direção do desenvolvimento das crianças usuárias de IC e explicaram as situações que levaram as mães a determinadas subjetivações.

Deste modo, os dados desta pesquisa foram organizados em unidades temáticas a partir das situações comuns emergidas de cada história de vida das mães.

A pesquisa foi aprovada pelo Comitê de Ética e Pesquisa da Universidade Federal de Alagoas - UFAL, sob o parecer de número 2.535.986 e respeitados os preceitos éticos que preconizam a Resolução 466/12 e a Resolução 510/16. No decorrer da pesquisa, foram considerados os pressupostos da bioética, configurados em sua Resolução. Foi apresentado às mães participantes da pesquisa a autorização institucional para realização da pesquisa e o Termo de Consentimento Livre e Esclarecido (TCLE) e, após a assinatura do termo, foi que se formalizou a participação do indivíduo na pesquisa.

\section{Resultados e Discussão}

Inicialmente, foram apresentadas as narrativas das mães participantes da pesquisa em suas vivências, em seus espaços de vida, permitindo compreender a mobilização das mães quanto à realização do IC, a inclusão social e escolar, o desenvolvimento da criança e seu trajeto para a (re)habilitação.

\section{As vivências de Neide}

Neide, 25 anos, casada, natural de Viçosa-Alagoas, ensino fundamental incompleto, dona de casa e duas filhas com idades de oito e seis anos. Relatou não trabalhar pela necessidade de cuidar das filhas e, em especial, da filha mais nova, usuária de IC. Sua filha, 6 anos, cursava o primeiro ano do ensino fundamental em escola pública e realizava acompanhamento na clínica de fonoaudiologia da UNCISAL uma vez por semana. Neide relatou que a gravidez não foi planejada e que a descoberta de uma nova gestação a deixou abalada:

A gravidez não foi planejada. Veio num dos momentos que menos esperava, um pouco difícil [respirou fundo], porque já tinha uma menina de nove meses, a mais velha tinha nove meses. Fiquei desesperada quando soube que estava grávida [abaixou a cabeça e respirou fundo], mas meu esposo me deu muita segurança. Só sou eu e ele e as duas meninas e foi ele quem mais me apoiou com isso.

Logo após o nascimento, ainda na maternidade, foi realizado o teste da orelhinha e Neide foi comunicada sobre a possível perda de audição da filha. Foram encaminhadas para a UNCISAL, onde novos exames foram realizados quando então foi confirmada a deficiência auditiva.

Sobre ter descoberto que ela era surda... [desviou o olhar] assim quando ela nasceu, não tive complicação nenhuma no parto nem nada. Mas quando ela nasceu o médico falou! Por que num faz o exame da orelhinha? Aí descobriram que ela era surda. Fiquei retornando lá na UNCISAL de quinze em quinze dias pra ver se tinha resolvido, mas não estava resolvendo.

$\mathrm{Na}$ UNCISAL, foram realizadas consultas com otorrinolaringologistas e fonoaudiólogos e, após avaliações, iniciou-se o uso do Aparelho de Amplificação Sonora Individual (AASI) e posteriormente as terapias com a equipe de fonoaudiólogos. 
Quando sua filha tinha aproximadamente três anos de idade, em uma das consultas com o otorrinolaringologista, foi informada sobre a possibilidade de realizar o implante, os procedimentos necessários e que seria necessário que Neide e seu esposo decidissem sobre o que acreditavam ser melhor para a filha. Após a decisão positiva da família em realizar o IC, foram encaminhados para Recife-PE, visto que em Alagoas o procedimento ainda não estava sendo custeado pelo Sistema Único de Saúde (SUS). Foi necessária ainda a intervenção da Defensoria Pública da União em Alagoas para que então o procedimento fosse realizado.

[...] ele quem encaminhou tudo, me deu os documentos... os papéis para dar entrada. Mas também só consegui porque dei entrada na defensoria pública pra ela fazer essa cirurgia, que eu também nem sabia que tinha esse implante coclear, não sabia, eles foram quem me explicaram.

O procedimento cirúrgico foi realizado no Instituto de Medicina Integral Prof ${ }^{\circ}$. Fernando Figueira (IMIP), no dia oito de março de dois mil e dezesseis. O IC foi realizado apenas no ouvido direito, sendo informado para a família que não havia verbas suficientes para realizar o implante bilateral, pois se tratava de um procedimento de alto custo.

Mesmo tendo diagnóstico precocemente, houve um longo intervalo de tempo para que o implante fosse realizado. A demora para a intervenção se deu pela falta de informação da família, pois não sabiam da existência do IC e que este era a melhor alternativa para a habilitação auditiva.

[...] eu não sabia que existia esse implante, já foi o Dr. que falou: "Sabia que tem implante coclear?" Eu não! Nem sabia o que era, aí ele explicou.

A cada quatro meses retornavam ao IMIP para realizar os mapeamentos do IC. As despesas com o deslocamento eram arcadas pela família, porém reembolsadas pela Secretaria Municipal de Saúde de Maceió, no setor de tratamento fora do domicílio.

Neide contou que a filha realizava terapias semanais com fonoaudióloga na clínica de reabilitação da UNCISAL. Relatou que depois do implante ela vinha melhorando consideravelmente, as demais pessoas que conviviam com a criança percebiam que ela realmente escutava. Seu vocabulário era composto por cerca de quatro palavras, as quais ela só pronunciava quando desejava.

[...] graças a Deus já tá ouvindo! Ouve, só não tá ainda falando direitinho. As palavrinhas que ela fala... papa...as vogais ela fala.

Sobre o processo de escolarização, Neide relatou que não teve dificuldades em matricular a filha na escola. Foi inserida na escola aos cinco anos de idade e foi bem recebida por toda a equipe da instituição. Era a única criança com deficiência auditiva e a diretora relatava para Neide, que tê-la na escola serviu como estímulo para que fosse possível receber outras crianças com deficiência. Narrou que a primeira escola era localizada em um bairro distante de onde residia e que o deslocamento era bastante cansativo, mas que atualmente tinha conseguido matricular as duas filhas em uma escola pública no bairro em que morava, o que otimizou a rotina da família.

Na nova escola, também não teve problemas para que a filha fosse aceita, mas reclamou sobre o comportamento, alegou que ela não se concentrava nas aulas, era dispersa e agressiva com os colegas de classe. Informou também que a filha não era alfabetizada, mas que a professora dizia que ela realizava as atividades em sala de aula. 
ler! Mas ela faz a tarefinha direitinho. Só é agitada, não sabe ficar sentada num canto, ela só quer tá pra cima e pra baixo dentro da sala.

Sua filha era bastante agressiva, principalmente com a irmã. E com determinada frequência, se irritava facilmente com os pais quando não era compreendida ou quando sua atenção era solicitada.

Hoje ela é um pouco agitada [balançou a cabeça e olhou para o chão], muito sapeca. Ela é um pouco agressiva com a irmã e com todo mundo, aliás, com todas as crianças, até adulto! Se mexer com ela, ela voa em cima de você! Ela começou assim agressiva depois do implante, quando a gente fala com ela, ela agora responde, grita com a pessoa... ela é muito estressada, ela não tem paciência, se você falar com ela, ela responde na mesma hora!

Emocionada, Neide falou sobre as dificuldades e que por vezes sentiu vontade de desistir.

Às vezes eu penso até em desistir de ir pra fono porque é muito complicado não ter apoio de família nem de ninguém [Abaixou a cabeça e respirou fundo]. Às vezes é que o pai ajuda, mas é muito complicado ter filho especial [estremeceu a voz].

Disse que se sentia feliz, pois a filha estava bem adaptada ao IC e que esperava realizar o outro implante. Estavam esperando o posicionamento da médica que realizava o acompanhamento no Instituto Materno Infantil de Pernambuco (IMIP). Porém, relatou insatisfação com o atendimento desta profissional, porque a comunicação era bastante difícil e que por vezes, precisou de orientações, mas a médica não estava disponível. Relatou o desejo de conseguir acompanhamento para a filha em Maceió e que desejava conseguir a realização do novo implante pelo SUS na própria cidade, porque assim as coisas seriam mais fáceis.

\section{As vivências de Cláudia}

Cláudia, nascida em Maceió, 43 anos, professora, casada, mãe de três filhos. Pós-graduada em educação especial, trabalha na rede municipal de ensino da cidade de Pilar-AL, como professora de sala de recurso multifuncional.

Seu filho, 11 anos, morava na cidade de Pilar-AL, com a mãe, o pai e dois irmãos mais velhos. Nascido no município de Maceió - AL, na maternidade do Hospital Santo Antônio, cursava o quinto ano do ensino fundamental em escola pública da rede municipal. Realizava acompanhamento fonoaudiológico na clínica da UNCISAL, no Centro de Capacitação de Profissionais da Educação e de Atendimento às Pessoas com Surdez (CAS) e em uma clínica particular no município de Maceió.

Decidida em não ter mais filhos, Cláudia contou que resolveu realizar a cirurgia de laqueadura tubária e, quando preparava-se para realizar os exames pré-operatórios descobriu que estava grávida de seu filho mais novo, uma gravidez não planejada:

A gravidez não foi planejada... de primeira assim... eu fiquei em choque, porque assim... eu já tinha dois filhos, meu marido estava desempregado, só eu trabalhando, e aí eu pensava muito como ia ser mais uma criança numa casa em que o pai não tinha nem perspectiva de quando ia arrumar um emprego [respirou fundo]. E isso me deixou muito preocupada, e aí eu tive uma rejeição da gravidez, porque minha mãe também ficou falando muito sobre isso, porque eu estava grávida já, com mais um filho e aí eu tive essa rejeição.

A gestação aconteceu de maneira tranquila, sem intercorrências, o pré-natal foi realizado com uma enfermeira numa Unidade Básica de Saúde (UBS) e o nascimento da criança se deu por um parto cesáreo. Relatou que o filho não realizou a triagem auditiva neonatal e quanto ao teste do pezinho houve certa demora para que fosse realizado. Com o passar dos meses, Cláudia foi percebendo o comportamento do filho: 
Ele ficava muito tempo muito quieto, ele era um menino que ele não chorava, nem com fome ele chorava! Muito quieto, quieto, no canto dele, ficava muito tempo olhando para a telha. Começou a andar com um ano, aí minha mãe foi quem disse a mim: "Esse menino tem algum problema". Porque a minha casa era uma casa barulhenta, eu tinha uma filha adolescente de onze anos, um filho de cinco e esses dois meninos fazendo muito barulho, brigava, ligava som e ele em nenhum momento se incomodava, nem se acordava!

Foram realizados alguns exames, porém o médico responsável afirmou que não se tratava de deficiência auditiva. Cláudia relatou que após essa afirmativa não buscou um diagnóstico, entretanto após um ano e três meses, diante de tanta insistência, seu filho foi encaminhado para a Associação dos Deficientes Físicos de Alagoas (ADEFAL), onde recebeu o diagnóstico de surdez severa profunda bilateral. Seu filho iniciou o uso do AASI, porém não apresentou resultados satisfatórios. Foi então que Cláudia tomou conhecimento do IC e dirigiu-se para a Secretaria Municipal de Saúde solicitando que o implante fosse realizado no IMIP, em Recife, visto que na época o procedimento não era realizado em Alagoas. Sem obter respostas, decidiu ir ao IMIP na tentativa de acelerar o processo:

Aí os médicos de lá passaram um exame. Aí eu consegui pelo plano de saúde né? Aí fez o exame e no exame deu que ele tinha uma má formação na cóclea, que se chama Síndrome de Michel e com essa má formação ele não tinha como fazer cirurgia, porque o implante ele não ia fazer a curvinha, porque não tinha a curvinha do caracol. Os eletrodos não iam funcionar. Aí eu chorei muito! Porque a esperança de que ele ouvisse era o implante [momento de emoção].

Após procurar uma outra opinião médica no próprio IMIP, surgiu a oportunidade de realizar o implante de tronco cerebral. Os exames foram novamente realizados e aguardaram o chamado para a realização da cirurgia.

[...] Eu disse que topava! Porque eu queria que ele ouvisse alguma coisa. A minha preocupação não era nem tanto que ele falasse, que pelo que eu estava vendo era impossível, mas que ele ouvisse alguma coisa... um barulho de um avião, uma moto, uma bomba, qualquer coisa... pra que ele sentisse algum, nem que fosse algum resíduo.

Após alguns meses receberam uma ligação do médico solicitando que se dirigissem ao IMIP para realizar o procedimento. Apenas treze eletrodos foram inseridos na cóclea devido à má formação. Seu filho saiu da sala de cirurgia com uma paralisia facial que ocorreu devido ao acometimento do nervo facial durante o procedimento cirúrgico.

Só entraram treze eletrodos! A audição dele ficou bem pouquinho, mas veio da cirurgia com derrame facial porque o nervo dele né? O nervo da face foi tocado. Foi muito angustiante, muito sofrido você ver o seu filho entrar numa sala de cirurgia perfeito e sair com o rosto todo troncho. E doía, né? Ele também tinha... a noite assim... ele dizia que o rosto tava doendo, isso tudo. Aí, nesse momento, eu me arrependi de ter feito o implante, mas eu já tinha feito e eu ia tentar reverter a situação do rosto.

A partir de sessões de fisioterapia, a paralisia facial foi revertida e o rosto de seu filho gradativamente foi retornando ao normal. No decorrer de um intervalo de dez meses, a criança teve três episódios de meningite consecutivos, foi quando Cláudia cogitou a possibilidade de retirar o implante, porém, repensou a possibilidade:

E aí a gente foi ver pra tirar o implante. Foi ver a condição de tirar o implante. Só que ele já estava tão bem com o implante... ele não falava totalmente, mas ele já falava papa, mama, água... ele prestava muita atenção em qualquer barulho. Ele assim... não falava! Mas ele estava atento a qualquer barulho de som... ele se mexia, dançava... [sorriu], mas não falava!

Após realizar novos exames, os médicos descobriram uma pequena abertura na meninge da criança, que era a causa das meningites recorrentes. Então, foi realizado um novo procedimento cirúrgico em que a abertura na meninge foi ocluída. 
[...] Ele teve uma crise de meningite e ficou com o pescoço duro. Levei para o hospital e a médica disse que era torcicolo e eu teimando que era meningite! E insisti que ela fizesse o teste e lá fez o teste e deu positivo. Quer dizer, se eu não tivesse o conhecimento, né? Tinha acontecido o pior.

Aí a médica disse: "Ele não vai pra UTI, porque ele já está num estado terminal e ele só vai ocupar o lugar de uma pessoa que pode sobreviver!" Eu disse "Eu pago o plano de saúde e eu exijo que ele vá, porque eu cheguei aqui dizendo a senhora que ele tava com meningite e a senhora não acreditou agora que ele tá assim!

E eu fiquei muito aperriada chorando... aí ele foi pra UTI. Na UTI eu fiquei junto com ele porque eu tinha curso de enfermagem e porque também ele não falava e na hora que ele acordasse, que eu tinha certeza que ele iria acordar, eu queria tá junto dele. E aí eu consegui ficar na UTI. No outro dia, o menino acordou, e tá aí o resultado do menino que ela disse que tava morto, né?

Três anos após a cirurgia apareceu um nódulo na região retroauricular da criança, que se rompeu e passou a drenar uma secreção. Cláudia retornou ao IMIP, onde realizou uma limpeza e iniciou a antibioticoterapia. Seis meses após, não ocorrendo melhora, realizaram uma tomografia e observaram que a parte interna do implante estava rodeada de secreção purulenta, sendo necessário um novo procedimento cirúrgico. Neste, foi retirado um colesteatoma que foi encaminhado para biópsia. O implante antigo foi retirado e inserido um novo IC, com uma tecnologia mais moderna e dessa vez conseguiram inserir todos os eletrodos. Cláudia contou que após a cirurgia, a audição do filho tinha melhorado muito e que estava aguardando o resultado da biópsia com medo, porém confiante que tudo daria certo.

Contou que juntamente com outras mães conseguiram que uma fonoaudióloga fosse realizar atendimento no município de Pilar onde residiam. Porém, devido à grande demanda de trabalho que a fonoaudióloga recebeu, foi necessário que ela fizesse um reajuste nos horários, coincidindo com o dia em que o menino realizava atendimento no Centro de Atendimento às pessoas com Surdez (CAS). Cláudia falou que preferiu continuar no CAS:

Eu ainda prefiro o CAS, porque lá além de ele ter uma professora, que ensina a língua de sinais já que ele não fala e ele tem que ter uma comunicação pras outras pessoas, nós temos lá também fonoaudióloga escolar, que é a Dr. Paula, aí com isso, pra mim é viável, porque também tem uma fono e tem a professora.

Quando inseriu o filho na escola, por ser professora da rede municipal, solicitou transferência para a escola em que ele estava matriculado. Nesta, ensinava no jardim de infância em uma sala ao lado do filho. Com o avançar da idade, o menino foi transferido para uma nova escola e novamente sua mãe solicitou transferência para a escola que ele estudava. Cláudia falou que o relacionamento do filho com os outros alunos no começo era difícil:

Os meninos ficavam assim... querendo se comunicar e ele não tinha libras, ele não tinha português, ele não tinha nenhuma língua. Aí era angustiante pra ele que ficava só olhando, e ele se excluía um pouco dos meninos, mas eu sempre procurava na hora do recreio tá presente, colocando os meninos pra brincar com ele, inventando brincadeira.

$\mathrm{Na}$ escola, seu filho tinha acompanhamento de uma intérprete de libras, que além de sua função, realizava atividades de alfabetização com exercícios que eram elaborados por Cláudia e entregues à intérprete. Como era professora da sala de recurso multifuncional na mesma escola em que o filho estudava, cedia sua sala todos os dias por cerca de duas horas para que a intérprete realizasse atividades diferenciadas e voltadas para alfabetização.

Cláudia falou que ele ainda não era alfabetizado, mas que conseguia juntar palavras simples de seu cotidiano e lê-las. Mas para que ele realizasse a escrita de uma palavra desconhecida, ela demonstrava as letras em libras e lhe mostrava a imagem para que ele soubesse do que se tratava. Falou que as dificuldades do filho, tanto na questão escolar, quanto na sala, poderiam ser consequência dos episódios de meningite, durante os quais ele passava muitos dias hospitalizado, sentia muitas dores de 
cabeça e deixava de usar o implante.

[...] A gente trabalha assim... Muita memorização, palavra e imagem. Mas eu ainda percebo assim... que a alfabetização dele é uma alfabetização de surdo, não é uma alfabetização de ouvinte, entendeu? Eu já tentei outros métodos, mas não consegui. Não sei se é porque durante esses episódios de meningite ele parava de usar implante. Ele ficou, ficava dezessete dias hospitalizado, vinte dias... aí tinha dor de cabeça forte! Ficava um tempo sem usar implante, ai essas coisas foram quebrando e ele não fala perfeito e nem lê.

Seu filho se esforçava para falar, porém Cláudia contou que nem todo mundo entendia o que ele queria dizer:

Ele tem muita dificuldade na oralidade, ele tenta, não dá pra compreender muito bem, só as pessoas de dentro de casa que entende muita coisa que ele fala, mas fora não! E também assim... eu acho que ele tem vergonha de falar porque ele já consegue perceber o som das pessoas e ouvir o próprio som, aí ele não quer falar, mas se ele se esforçar pra falar ele fala!

Quando faltava algum professor na escola, Cláudia entrava na sala e ensinava libras para as outras crianças, ensinava seus nomes e sinais para a comunicação básica. As aulas de libras geralmente aconteciam na sala do filho. Contou que quando ele mudasse de colégio novamente, devido à idade, não pediria transferência:

[...] Eu não vou pedir transferência pra lá porque ele já tá maior, ele já consegue se comunicar, lá tem intérprete sabe? Aí eu não pretendo ir, pra essa ele vai ficar lá só, até pra ele começar a se sentir independente, porque ele se sente muito protegido comigo na escola.

[...] Porque agora ele vai começar outra fase da vida! Daqui a pouco vem faculdade, vem tudo e eu não vou poder tá. Aí eu já tenho que começar agora nesse próximo ano a deixar ele só.

Finalizou contando que após quase dez anos de IC a habilitação ainda era muito lenta e exigia bastante sacrifício. Relatou também que o filho já discriminava os sons do vento, do telefone, procurava a voz dela e atendia seus chamados, que sabia o que era a chuva e o barulho de alguém chamando no portão.

\section{As vivências de Maria}

Maria, 40 anos, casada, é mãe de três filhos. Funcionária pública municipal, trabalhava como agente comunitária de saúde numa UBS, no município de Rio Largo. Sua filha, 8 anos, a mais velha de três irmãos, natural de Maceió - AL, nasceu na Maternidade Escola Santa Mônica, cursava o terceiro ano do ensino fundamental em uma escola particular no município de Rio Largo, onde residia com a mãe e dois irmãos.

Maria contou que um ano após o casamento com seu esposo, a filha nasceu. No início, a gestação se desenvolveu com tranquilidade, mas por volta dos quatro meses de gestação, Maria passou a apresentar elevações na pressão arterial, o que a levou a realizar o pré-natal de alto risco e ser acompanhada no Hospital Universitário Prof ${ }^{\circ}$ Alberto Antunes, em uma clínica particular na cidade de Maceió e na Maternidade Escola Santa Mônica.

A pressão não cedia! Sempre alta e eu trabalhando, trabalhando... ficava de atestado. Mas aí quando vencia o prazo tinha que trabalhar. Infelizmente a condição era essa.

Por volta das vinte e nove semanas, durante uma consulta de rotina com a obstetra da clínica particular, Maria contou que ao mensurar a pressão arterial, verificou-se que estava muito elevada e soube que sua filha nasceria naquele dia, não poderiam mais esperar. 
Aí subi pra sala do pré-parto. Fui chegando e já foram me colocando no soro, preparando a sala de cirurgia e assim a gente percebia que a médica estava muito nervosa, porque ela, ela dizia mesmo ao meu esposo, ou ela ou a criança, uma das duas a gente vai ter que salvar né? E aí começou o desespero da família!

Sua filha nasceu com 29 semanas, pesando 920 gramas e medindo 36 centímetros. Maria explicou que logo após o nascimento, a filha foi encaminhada para a UTI neonatal enquanto ela permaneceu na sala de cirurgia. Quando já estava na sala de recuperação, a equipe de médicos conversou com ela e lhe disseram que sua filha era prematura, que estava na UTI neonatal e que tudo daria certo.

E aí foi tirando e só foi dizendo assim: "Olhe mãe! A gente tem que correr pra colocar ela numa UTI neonatal!” Ai pronto! Eu não escutei choro, ela não chorou, não a vi, eu só escutava elas dizendo: "Novecentos e vintegramas! Trinta e seis centímetros!" Rápido, rápido!" Ela tava roxinha já, aí correram com ela pra UTI e eu fiquei na mesa de cirurgia.

Após alguns dias, Maria recebeu alta. Disse que a equipe da maternidade solicitou que ela fosse para casa, pois não haviam mais leitos disponíveis e que seria disponibilizada uma ambulância para que viessem visitar a filha todos os dias. Ela negou-se a sair da maternidade, sendo então disponibilizado para ela um colchão para que ficasse em uma das enfermarias, onde permaneceu por três dias até que um leito foi disponibilizado.

Maria contou que cinco dias após o parto, foi permitido que ela visse a filha, mesmo que ainda não podia pegá-la no colo e nem amamentar, apenas conversava e a tocava levemente.

Eu chorava toda santa noite porque não podia ver ela ainda. Aí quando foi com cinco dias me liberaram pra eu descer e ver, mas a impressão sabe... pequena, pequena que cabia na palma da mão, bem pequenininha mesmo!

Durante dois meses sua filha permaneceu na UTI neonatal e Maria na enfermaria Mãe Canguru. Maria contou que todos os dias era uma incerteza em relação ao estado de saúde da filha.

Todo dia quando eu acordava tinha notícia que algum bebê, que algum recém-nascido tinha falecido, tinha vindo a óbito. Aí toda vez quando a gente acordava já chegava uma psicóloga no quarto. Aí você já tomava... você já ficava imaginando: é o meu agora? Foi o meu? Porque era essa a incerteza, hora era estável hora não... a condição de saúde deles.

Após receber alta da UTI neonatal, sua filha permaneceu durante mais um mês com ela na enfermaria Mãe Canguru, até receber alta para casa.

Foram realizados a triagem auditiva neonatal (teste da orelhinha), teste de Guthrie (teste do pezinho) e o teste do reflexo vermelho (teste do olhinho). Sua mãe contou que durante o teste da orelhinha surgiu a suspeita da deficiência auditiva. A médica a aconselhou observar o desenvolvimento da criança e aguardar, visto que a mesma tinha nascido de parto prematuro.

E a gente observava que ela dormia demais, ela dormia demais! Assim... som passava ela não se assustava, batia a porta ela não piscava o olho, não tomava susto e só dormia!

Quando sua filha estava com seis meses de vida, durante uma consulta de rotina com a pediatra, Maria solicitou que fizessem novamente o teste da orelhinha.

Aífez novamente os exames, foi quando ela fechou né? Foi quando ela disse: “Olhe, pelo resultado ela tem uma surdez profunda, o grau dela é profundo! Não se reverte. A gente vai tentar estimular e vamos ver se com o aparelhinho, o 
AASI, ela responde.

A filha iniciou o uso do AASI e as terapias com fonoaudiólogo. Maria contou que mesmo com todo o estímulo que ela recebia, não apresentava um desenvolvimento significativo. Ao conversar com uma otorrinolaringologista, que atendia sua filha na UNCISAL, tomou consciência da existência do IC e da possibilidade da realização do mesmo no IMIP em Recife.

Quando sua filha estava com um ano e três meses foram chamadas para o IMIP. Maria contou que ao chegar lá, toda uma equipe já os aguardava. Passaram por otorrinolaringologista, psicólogo, fonoaudiólogo e assistente social. Vários exames foram realizados e em seguida foram colocadas em uma lista de espera, aguardando a realização do implante.

Explicaram o que era o implante. E que a gente poderia ter duas certezas: positiva e negativa. Porque tem criança que evolui, mas tem criança que não! Aí é responsabilidade dos pais assumirem isso e ajudarem, serem parceiros. Mas aí, como o nosso desejo era que ela escutasse, que ela se tornasse independente, a gente aceitou! Seja o que Deus quiser, a gente tá pronto pra tudo.

A cirurgia durou cerca de quatro horas e sem intercorrências. Após cinco dias de hospitalização, Maria voltou para casa com a filha. Com dois meses retornaram ao IMIP e foi então que aconteceu a ativação do IC.

Mas foi uma... como é que se diz? Um momento assim... que você desejou tanto e quando aconteceu sabe? Foi só alegria! Porque na hora da ativação, a fono colocou os eletrodos, ligou o aparelhinho, começou a falar com ela, ela já olhava assim procurando o som e chorando, sabe? Foi uma emoção! Que eu disse: "Meu deus a minha filha agora escutou!" Ai foi só alegria!

Maria continuou indo periodicamente para Recife com a filha para realizar os mapeamento do IC. Fazia atendimento com fonoaudiológico na UNCISAL e com dois anos de idade também passou a realizar terapia no CAS.

Aí eu saía de manhã! Cinco e vinte da manhã. Eu pegava o ônibus com ela, uma mala de roupa, comidinha, papinha, fraldas, trocas de roupas, ia embora! Cinco da manhã ia pra UNCISAL, da UNCISAL ia para o CAS. Aí chegava em casa oito horas da noite, de ônibus, sol, verão, inverno o que fosse! Não interrompia o tratamento... e ela novinha. Até então, todo o trajeto dela até agora foi todo pelo SUS. Ela tem plano, mas tudo que a gente tem e consegue pra ela eu prefiro o SUS, porque eu sei que eu tenho um amparo, que é tudo que eu posso ter.

Maria contou que a última conquista foi o aparelho de sistema Frequency Modulation (FM), para que a filha utilizasse na sala de aula no intuito de melhoria na compreensão da fala da professora. Contou também que enfrentou muitas dificuldades para que a filha tivesse direito à carteirinha que garante gratuidade no transporte público.

É triste hoje você ter uma criança na situação dela, né? Surda e com implante. Graças a Deus financeiramente a gente tem uma condição boa e quem não tem? E a mãe que não tem? Né? Que não tem essas informações? Que não é orientada, que não busca... ela sofre! Porque não é brincadeira! O custo e a manutenção do implante é alto e quando você chega diante de uma assistente social, coloca a sua situação e ela diz a você que você não tem direito ao BPC... isso é o cúmulo do cúmulo!

Sua filha estudava numa escola particular no município de Rio Largo e estava nessa escola desde os dois anos de idade, pois acreditavam que isso seria mais um fator que iria favorecer seu desenvolvimento. A equipe pedagógica já havia tido experiência com outros alunos implantados. Maria falou que decidiu colocar a filha numa escola particular, pois tinha a certeza que a filha seria bem cuidada.

Olhe aqui é o município de Rio Largo. Se você chegar em uma das escolas públicas aqui e perguntar qual é a escola 
que tem intérprete? Nenhuma! Nenhuma escola pública aqui tem intérpretes, como é que eu vou confiar?

Eu juro a você... eu tenho medo de colocar ela numa escola municipal pública, porque eu vejo o descaso que é, eu vejo... Eu percebo o descaso com aqueles que têm deficiência e numa escola particular não! Eu sei que eu posso cobrar de um professor, eu posso cobrar da direção, eu posso cobrar da instituição porque eu estou pagando, então pra mim eu me sinto mais segura no particular, porque eu sei que ela vai render.

A criança ainda não era alfabetizada, a leitura baseava-se em palavras simples de seu dia-a-dia, a escrita também ainda com dificuldades. Porém, possuía uma boa compreensão de textos e problemas matemáticos.

Hoje ela consegue escrever, ler... Ela consegue pouco, tem que puxar muito, mas ela consegue... Mas dizer que é cem por cento alfabetizada não! Ainda não! Matemática é excelente! As perguntas do irmão, que eu estou respondendo com o irmão, soma, subtração ela já diz a resposta a ele. Aí eu digo: Não! Calma, é ele! Mas assim a gente já entende que ela já sabe que ela evoluiu, que ela já progrediu, não porque a gente privou, a coitadinha, a bichinha é surda, bichinha nada! Ela é igual a todo mundo! Então tudo que a gente faz por ela e pra ela é pensando nisso... dela ser independente!

Maria relatou sobre a rotina, que por ser funcionária pública teve que batalhar pelo direito de duas vezes na semana sair com a filha para realizar as terapias.

É preciso a gente lutar, botar mesmo a boca no trombone, enfrentar sem medo pra gente ter o nosso direito e eles terem o espaço deles no mundo, mas não é fácil, são barreiras e barreiras!

É desgastante! Porque você se desgasta, tem que se virar nos trinta pra ser dona de casa, profissional, mãe, mulher... tem tempo que nem tem tempo pra você! Tempo pra mim é pouco, é pouco! Porque o tempo que eu tenho é dos meus filhos.

A gente se cansa, a gente às vezes se maltrata porque não tem tempo pra gente, sabe? São vinte e quatro horas pensando nela! Pra poder ter tempo e poder assim respirar de noite, descansar pra poder no outro dia tá em pé, porque senão a gente não aguenta não! É uma bomba andando... qualquer dia desse explode! Se você não tiver esse pensamento, se não alinhar, você se estressa e esgota, e você não tem prazer de fazer nada!

Maria relatou que em diversas ocasiões precisou contar para pessoas, que viam sua filha em locais públicos, o que era o implante, que ela era deficiente auditiva e que se tratava de uma tecnologia que permitia que ela escutasse. Falou que colocar a filha para realizar terapia no CAS foi um meio de oferecer mais uma oportunidade de comunicação e promover a sua independência. No começo, encontrou uma certa resistência dos profissionais para que a filha aprendesse libras, pois acreditavam que assim ela não teria o prazer de usar a oralização.

Ela hoje tem oito anos. Há cinco anos ela foi implantada, cinco anos de implante. Hoje ela fala, mas fala pouco. Então eu vejo o tempo passar... então se o tempo pra ela está passando, eu não quero que ela fique nessa dependência de oralização. Poucas palavras para se expressar, então toda a oportunidade que ela tiver, em relação ao ensino e a evolução dela, eu tô me arriscando. É libras, aprenda libras! Oralização, vai para a oralização! Eu tento de tudo pra que ela tenha a comunicação, para que ela saiba se comunicar!

Quando iam para o CAS, enquanto a filha estava em terapia, sua mãe contou que ela e outras mães ficavam reunidas em uma sala aprendendo libras, trocando experiências, discutindo sobre tudo de novo que pudesse beneficiar seus filhos. E isso a animava porque a troca de experiências era importante para continuar e que isso era uma fonte de apoio, além do apoio que estava recebendo pela família.

Quando vou para as terapias, é a minha sogra quem pega meus filhos na creche, leva pra casa, dá banho e janta. Aí 
vou direto pra casa dela. A gente janta com todo mundo. Quer dizer, isso pra mim já é uma ajuda imensa! E quando chego, ainda encontro uma mesa posta com café, com sorriso e alegria. Pra mim, com isso, eu ganhei o dia!

Maria falou sobre o desejo de ouvir a filha falando. Concluiu dizendo que ainda iria viver muita coisa com a filha e que precisava ser forte para oferecer o melhor para ela e que sem o apoio da família não conseguiria.

\section{As vivências de Cristiane}

Cristiane, 34 anos, casada, natural de Maceió-AL, ensino médio completo, atendente de telemarketing, três filhos, a filha mais velha com 16 anos, residia com o pai. Os outros dois filhos eram resultado de seu atual casamento.

Sua filha, 11 anos, residia em Maceió-AL com o pai, a mãe e um irmão mais novo de 7 anos, cursava o $4^{\circ}$ ano do ensino fundamental em uma escola privada. Realizava acompanhamento fonoaudiológico na clínica da UNCISAL e na Associação dos Amigos e Pais de Pessoas Especiais (AAPPE). Nasceu de parto vaginal na maternidade do hospital Unimed em Maceió-AL.

Cristiane relatou que não foi uma gravidez planejada, mas aconteceu tranquilamente, sem intercorrências ou complicações, porém, em uma das testagens sorológicas realizadas durante a gestação, o vírus citomegalovírus apareceu como reagente. Porém, a obstetra que a acompanhava não a informou sobre o vírus, tratamento ou riscos que poderia trazer para a criança.

Porque no exame, que é feito no pré-natal, exame de sangue, detectou essa situação que tava com o vírus reagente e passou pra a menina. Mas ela não me falou nada e como eu não sou médica, não tenho conhecimento nessa área, pra mim estava tudo normal, então quando ela nasceu foi quando se detectou que eu tinha passado o vírus pra ela.

Logo após o nascimento de sua filha, diagnosticou-se que Cristiane tinha tido o citomegalovírus na gestação e por isso foram realizados exames sorológicos na criança. Os exames foram enviados para fora do estado de Alagoas para que pudessem ser analisados e os resultados comprovaram a infecção.

Na triagem auditiva, onde foi diagnosticada com deficiência auditiva. Porém, somente quando a filha estava com sete meses de vida, a deficiência auditiva foi realmente confirmada. Aos oito meses, foi iniciado o uso do AASI e as terapias com fonoaudiólogo na UNCISAL.

Pra mim e pra o pai foi um choque! A gente ficou desnorteado com a situação, mas fomos apoiados pela família e pelos médicos que também nos confortou com palavras de carinho.

Quando ficou grávida de seu filho mais novo, Cristiane relatou que sentiu bastante medo de que ele também fosse afetado pelo citomegalovírus. Relatou que depois de um tempo ele apresentou uma perda auditiva, mas que havia possibilidade de ser causa genética, visto que um dos filhos, do casamento anterior de seu esposo, também possuía deficiência auditiva.

Quando sua filha estava com um ano e meio de idade, Cristiane tomou conhecimento sobre o IC, foi quando encaminhou toda a documentação necessária para se candidatar ao IC no Centrinho em Bauru. Ao procurar o Tratamento Fora de Domicílio (TFD) a respeito do auxílio deslocamento, foi informada de que em Recife o implante já estava sendo realizado. Foi então que se dirigiram ao IMIP, fizeram uma pré-inscrição para a realização do IC e em seguida foram avaliados por médicos, fonoaudiólogos, psicólogos e assistente social. Um dia antes de sua filha completar dois anos, o IC foi realizado.

Cristiane relatou que quando a filha realizou a cirurgia, as duas ficaram sozinhas no IMIP, porque não tinham familiares em Recife e o pai precisou voltar para Maceió. Na primeira noite após o implante, Cristiane precisou passar uma noite inteira com a filha nos braços para que ela não perdesse o acesso venoso periférico. Muitas cirurgias foram realizadas no dia e Cristiane disse que se sentiu desassistida. Contou que mesmo com todo o cuidado, o acesso foi perdido e sua filha chorava muito, pois já 
haviam tentado várias vezes um novo acesso sem sucesso.

Teve que furar todo o corpo, pé, braço, mão, onde tinha veia que pudessem furar eles furaram e não conseguiram. E depois de muito reclamar, uma médica disse que tinha que furar na cabeça porque ela tinha que tomar o remédio, não podia ficar sem tomar os antibióticos que tinham passado pra não ter rejeição do implante e eu fiquei muito nervosa, chorei muito porque tava sozinha e não sabia o que fazer.

Ela recebeu alta no dia seguinte e foi para casa com Cristiane. Dois meses após a cirurgia, voltaram ao IMIP para realizar a ativação do IC juntamente com as fonoaudiólogas.

Então na hora foi um choque pra gente! Ela chorou muito, quando ouviu a médica chamar pelo nome dela ela chorou! Então pra gente foi muito, foi lindo, foi muito lindo! Ficamos emocionados só de saber que a nossa filha estava ouvindo, então assim... foi maravilhoso!

No início, a criança apresentou certa rejeição ao IC e não queria usar por mais que seus pais insistissem. Permaneceu assim com essa resistência por cerca de quatro anos após a ativação, porém, foi se adaptando e já estava usando o implante corretamente. Cristiane contou que a filha já percebia a importância do IC para se comunicar.

Os mapeamentos do IC estavam atrasados e Cristiane contou que todas as vezes em que iam ao IMIP a filha reclamava da programação e a médica resolvia não ajustar, para que ficasse confortável para a criança. Já faz um ano que não voltavam em Recife e que não recebiam notícias de quando seria o próximo mapeamento. Sua filha reclamava bastante de dores de cabeça, o que de acordo com a otorrino que a acompanhava, poderia ser causada pelo não mapeamento do implante.

Sua filha tinha uma pequena noção de libras e nas duas instituições que realizava terapia, a oralização era o foco, Cristiane contou que já havia realizado um curso básico de libras e, como as aulas aconteciam na UNCISAL, cerca de uma hora antes da terapia com fonoaudiólogo que a filha realizava, as duas iam juntas e acompanhavam as aulas e por isso adquiriu conhecimento da língua de sinais.

Cristiane contou que foi orientada a matricular a filha em escola regular, pois isso a ajudaria em seu desenvolvimento, não enfrentou dificuldades para matricular a filha e que ela sempre foi bem recebida. Na escola, a professora após passar o conteúdo para toda a turma, chamava a criança e explicava para que ele pudesse compreender melhor. Relatou que a filha ainda não conseguia ler palavras desconhecidas que não faziam parte de seu cotidiano e que apresentava certa facilidade em escrever. Durante a manhã, ela ficava na escola e, no período da tarde, na creche que pertencia à escola, até que Cristiane chegasse do trabalho.

Cristiane contou que por causa da distância entre o trabalho, sua residência e os locais de terapia, muitas vezes não conseguia chegar a tempo para levar a filha aos atendimentos:

Nos dias de terapia eu solicito que a empresa me libere para trabalhar de seis ao meio dia. Aí é quando eu consigo chegar às terapias, às vezes ocorre de não conseguir, porque o ônibus demora muito... Então, às vezes acontece de eu não conseguir vir a terapia, ou às vezes acontece dela tá doente ou eu estar doente, porque não tem outra pessoa que possa trazê-la a terapia. Se eu estiver doente, eu não consigo trazer, porque além de eu trazer ela, preciso levar também meu outro filho. É cansativo né? Mas pra mim é uma vitória! Só de eu ouvir a minha filha falar mamãe e falar outras palavras, para mim já é uma grande vitória, pra mim é maravilhoso!

A criança apresentava a linguagem oral em desenvolvimento, as palavras que pronunciava eram audíveis e de possível compreensão. Cristiane contou que apesar disso, às vezes sentia dificuldades para lidar com a filha, pois não sabia até que ponto ela compreendia o que estava sendo falado. 
Para lidar com ela assim é muita dificuldade. Pelo menos eu, assim... falando por mim, eu não sei até que ponto ela compreende, até que ponto ela já aprendeu. Então pra mim isso é muita dificuldade, saber até que ponto ela já compreende. Sei que ela é uma menina, muito inteligente, muito esperta, mas a gente tem uma certa dificuldade de trabalhar isso com ela também.

Cristiane encerrou relatando o quanto era feliz por ter a filha, que era grata pela vida e que a deficiência auditiva não impedia a sua filha de ser uma menina feliz, alegre e amorosa.

Eu agradeço a Deus todos os dias, porque você tem uma filha igual a ela, porque tem muitos que têm outras deficiências e a necessidade é muito maior e ela só tem uma deficiência auditiva!

\section{Discutindo as vivências das mães a partir do referencial teórico}

A criança com deficiência auditiva muitas vezes apresenta dificuldades em seu desenvolvimento e a necessidade de se comunicar e expressar suas vontades acarretam, muitas vezes, alterações em seu comportamento, o que pode ocasionar problemas no seu desenvolvimento cognitivo e no comportamento, tal como a agressividade. Ao realizar o IC, cria-se a possibilidade da linguagem oral, a criança sente-se integrante de processo de comunicação no contexto familiar, passa a ser escutada e sente a necessidade de ser compreendida (Frota, Amaral, Nobre \& Barbosa, 2012). Isso reafirma a importância de tornar a criança integrante do processo comunicativo e da aquisição da linguagem para o seu desenvolvimento cognitivo e social.

Ao descobrirem a deficiência auditiva, as mães se deparam com incertezas a respeito do futuro de seus filhos, mas o IC trouxe a garantia de independência no futuro e melhoria no desenvolvimento. Ao realizarem um estudo com pais de crianças usuárias de IC, Yamanaka et al. (2010) puderam comprovar que os pais viam no IC uma solução consoladora diante da descoberta da deficiência auditiva. A decisão para a realização também era influenciada pela qualidade da informação que as mães recebiam, além da maneira acolhedora pela qual eram recebidas pelos profissionais de saúde.

Com a realização do IC, foi necessário que as famílias se adaptassem às novas demandas dos filhos, assumindo o papel de principais incentivadoras e mantenedoras para o desenvolvimento deles, levando a uma sobrecarga pessoal e, muitas vezes, necessitando, que nos dias em que os filhos realizavam terapias, remanejar os horários da jornada de trabalho para então acompanhá-los, ocasionando desgaste físico e emocional (Nascimento, Schiling, Ubal, Biaggio \& Kessler, 2016).

A respeito disso, Vygotski (1934/1997a) ressalta a capacidade de enfrentamento de obstáculos e dificuldades que o defeito traz consigo, estes passam a assumir uma função de estímulo para que o indivíduo venha a desenvolver caminhos alternativos e adaptar-se de maneira a caminhar com o curso do desenvolvimento, de modo a compensar o defeito, estabelecendo um equilíbrio que anteriormente foi rompido.

Entre as crianças, três receberam um diagnóstico precoce. Logo após o nascimento, com a realização da Triagem Auditiva Neonatal (TAN), a deficiência auditiva foi sinalizada e antes mesmo de um ano de idade as crianças já faziam uso do AASI e terapias com fonoaudiólogo. Com exceção do filho de Cláudia, que não realizou a TAN e teve o diagnóstico atrasado, a família tomou conhecimento da deficiência auditiva somente após um ano de idade.

Para Bicas, Guijo e Delgado-Pinheiro (2017), ao realizar o IC precocemente, de preferência antes dos 12 meses de vida, iniciar terapias com fonoaudiólogo e com a devida participação familiar, a criança pode atingir o desenvolvimento esperado para sua idade. O primeiro ano de vida é crucial para que a criança adquira a fala e a linguagem, devido ser neste período onde ocorre o ápice de maturação do sistema auditivo central sendo o de maior plasticidade auditiva (Rodrigues, Loiola-Barreiro, Pereira \& Pomilio, 2015). Porém, observou-se que as crianças deste estudo realizaram o IC somente após os dois anos de idade, sendo o mais tardio o da filha de Neide aos 4 anos de idade.

Na percepção das mães, a audição era peça fundamental para a independência dos filhos. Para Yamanaka et al. (2010), o IC trazia consigo a possibilidade da criança ouvir, em conjunto com a expectativa para a aquisição da linguagem oral, de forma 
a torná-los independentes e autônomos, preparados para encarar a sociedade e o futuro. E assim, as mães se tranquilizaram de que mesmo ausentes, seus filhos teriam uma vida tranquila.

Com a adaptação ao IC, a realização de terapias com fonoaudiólogo e a participação efetiva da família, o desenvolvimento da linguagem oral ocorre de maneira única e diferenciada em cada criança, sendo um dos potenciais facilitadores desse processo a intervenção precoce.

Dentre as crianças, a filha de Neide era a que possuía o vocabulário mais restrito e com maiores dificuldades na comunicação, sendo também a que realizou o IC mais tardiamente em comparação às outras. Colalto et al. (2017) reforça que as crianças implantadas apresentam vocabulário de resultados variados, mas elas podem atingir os resultados esperados, tanto para a idade auditiva, quanto para a idade cronológica, desde que estimuladas precocemente e com a participação da família.

Com a experiência adquirida após a realização do IC e o acompanhamento do desenvolvimento dos filhos, as mães passam a atribuir não somente mais a audição, mas agora também a linguagem, como os pilares necessários para a real independência dos filhos. Para Souza (2013), a linguagem, além de exprimir sentimentos e pensamentos, é um instrumento de comunicação e de interação social.

A partir dessa percepção e diante das dificuldades que rodeiam o desenvolvimento da linguagem oral e a necessidade de compensar o déficit na comunicação, fez com que Maria e Cláudia buscassem como alternativa a Língua Brasileira de Sinais (LIBRAS). Elas consideravam a capacidade de comunicação dos filhos restrita e viam a importância da aquisição de uma linguagem que não abrangesse somente a família, mas que possibilitasse a interação com a sociedade.

Porém, o uso da língua de sinais, como um sistema cultural auxiliar, envolve processos psicológicos diferentes, podendo assumir a mesma função cultural na conduta da criança e adquirir mecanismos fisiológicos similares ao considerado normal (Vygotski, 1929/1997b).

Ao relatar a atual situação da filha, Maria reforçou a importância não só do IC, mas também das oportunidades que envolvem tanto a linguagem oral, quanto o uso de libras para o desenvolvimento e o quanto são essenciais para que a criança se sinta parte integrante da sociedade.

Vygotski (1929/1997b) ressaltou que a deficiência auditiva não traz consequências relativamente graves para o desenvolvimento geral da criança, porém, a ausência da linguagem provocada por este defeito, a ausência da fala humana, compreende uma das complicações mais dolorosas do desenvolvimento cultural.

Todas as crianças ingressaram e estavam matriculadas em escola de ensino regular, o que, para Costa e Barbosa (2017), exige um trabalho pedagógico pautado nas potencialidades da criança, na perspectiva da educação inclusiva voltada às necessidades e a realidade da criança, para assim proporcionar o aprendizado de maneira eficaz.

As mães relataram que não enfrentaram dificuldades em inserir seus filhos no ambiente escolar. Isso é preconizado pelas leis brasileiras voltadas para a educação, as quais preconizam a inserção da criança com deficiência preferencialmente em estabelecimentos de ensino regular, sejam eles públicos ou privados, visando a inclusão do indivíduo em todas as áreas da sociedade (Brasil, 2004).

Essa concepção das mães sobre a escolarização precoce foi confirmada por Martins, Aguiar e Carrapato (2013). As autoras enfatizaram a importância de inserir as crianças usuárias de IC no ambiente escolar regular o mais precocemente possível, visto que a convivência com ouvintes irá proporcionar maiores oportunidades de experiências auditivas, possibilitando o desenvolvimento da audição, da linguagem oral, o fortalecimento do aprendizado e a interação social.

Vygotski (1932/2012) também enfatizou a importância do ensino e da aprendizagem em prazos adequados de acordo com a idade da criança, ressaltando que dessa maneira a aprendizagem ocorrerá de maneira produtiva e proveitosa. Todavia, muitas vezes, as atividades realizadas em sala de aula não eram direcionadas para suas necessidades, a criança não estava incluída de maneira adequada, fato esse que pode explicar seu comportamento em sala de aula. 
A respeito disso, para Vygotski (1929/1997b), a escola não deve apenas se adaptar às inadequações da criança, mas também lutar contra elas e superá-las, pautando-se na compensação e na educação social, fazendo uso de um caráter criativo. Em relação a alfabetização, nenhuma das crianças eram alfabetizadas, porém, percebeu-se que as crianças que possuíam um atendimento especializado em sala de aula, voltado para suas necessidades e fragilidades, onde eram abordadas suas principais dificuldades, progrediram em relação à leitura e à escrita.

Importante ressaltar os apontamentos de Maria e Cláudia, as quais enfatizaram a importância de se trabalhar os conteúdos fazendo uso de metodologias que proporcionem o maior entendimento dos filhos e relacionadas às suas necessidades. A velocidade da fala, o uso de imagens, o posicionamento da criança próximo ao professor possibilita uma melhor compreensão e qualidade no aprendizado. Segundo Souza (2013), o uso de figuras, enquanto recurso visual, é extremamente válido no processo de letramento de alunos com deficiência auditiva.

Devido ao tempo de privação sonora a criança apresenta dificuldades escolares, devido estar se adaptando e aprendendo a relacionar audição, fala e pensamento. Deve-se criar estratégias para incluir a criança e ensinar os conteúdos, lembrando-se que o início de sua vida auditiva se deu quando seu IC foi ativado, diferente de uma criança ouvinte. O processo de escolarização se torna um desafio para professores, pais e para as próprias crianças (Silva, 2016).

Para Vygotski (1932/2012), o campo prático na defectologia da educação é confrontado com tarefas cuja solução exige um trabalho criativo de organização de formas especiais para resolver problemas relacionados ao defeito, sendo necessário encontrar uma base sólida para unir teoria e prática.

Deste modo, foi possível observar as dificuldades encontradas frente a escolarização efetiva das crianças usuárias de IC e a necessidade do preparo escolar para recebê-las, carecendo do uso de estratégias e metodologias voltadas para cada situação e com o objetivo de proporcionar o aprendizado, estimulando os fatores cognitivos e acoplando audição, fala, pensamento e compreensão.

Todo o percurso das mães com seus filhos foi permeado pelo vínculo eterno de amor, compaixão e do entregar-se sem cobranças. No que diz respeito às vivências entre mães e filhos com deficiência, percebeu-se sentimentos como a coragem e a superação de enfrentar árduas situações que lhes são impostas, adquirindo a capacitação e a competência necessária através de suas vivências e com sua resiliência adquirem o fortalecimento psicológico para enfrentar as dificuldades da vida (Guerra et al., 2015).

\section{Considerações Finais}

A partir do conhecimento das vivências das mães do estudo, foi possível entender os aspectos que potencializaram e/ou fragilizaram o desenvolvimento das crianças. Além de conhecer os desafios impostos pela deficiência auditiva que foram enfrentados pelas mães, nas suas expectativas, medos e planos para o futuro dos filhos.

Apesar da crescente expansão do IC na sociedade, as mães enfrentaram o despreparo do SUS não somente no Estado de Alagoas, mas em nível nacional para o procedimento, o que ocasionou uma intervenção tardia, além de vivenciar as fragilidades do sistema escolar.

A mobilização das mães constituiu o principal alicerce na vida das crianças. A busca pelo IC, a inserção e a inclusão escolar e suas abdicações pessoais reafirmaram a posição das crianças como sujeitos sociais.

Ao integrar saúde e educação é possível estabelecer um elo que proporciona o desenvolvimento dessas crianças. Ao descobrir a deficiência auditiva precocemente, com a realização do IC em tempo hábil, o uso de metodologias pedagógicas que busquem o aproveitamento de crianças usuárias de IC em sua escolarização e a participação familiar eficaz, é possível alcançar os marcos de desenvolvimento esperados para a idade da criança. 
Observou-se a necessidade de criação de redes estaduais ativas e funcionantes de apoio às mães de crianças usuárias de IC, além da criação de leis que venham a garantir efetivamente o direito de acompanharem seus filhos, sem privá-las posteriormente de momentos com os mesmos, alongando a jornada de trabalho.

Acredita-se que a abordagem teórica metodológica adotada neste estudo, estimule novas pesquisas sobre mães de crianças usuárias de IC, fortalecendo esse método de análise para esse grupo. Através deste estudo, evidenciou-se a importância de compreender as raízes sociais e os contextos históricos defendidos por Vygotski, que envolvem as vivências das mães participantes e de seus filhos, emergindo do passado ao futuro, possibilitando conhecer suas histórias e o desenrolar das ações no curso de seu desenvolvimento e de suas realizações.

Observa-se a importância do desenvolvimento de estudos futuros onde sejam abordados além da perspectiva da família, também a da criança, suas necessidades, percepções e formações psicológicas e socias frente a realização do IC, bem como o desenvolvimento de instrumentos adaptados para orientação e representatividade para essas crianças.

\section{Referências}

Bicas, R. S., Guijo, L. M., \& Delgado-Pinheiro, E. M. C. (2017). Habilidades auditivas e de comunicação oral de crianças e adolescentes deficientes auditivos e o processo de reabilitação fonoaudiológicar Revista $\quad$ CEFAC, $479(4), \quad 465$ https://www.scielo.br/j/rcefac/a/McjQnj5ZCsSX6LWTzHfgzZK/?format=pdf\&lang=pt

Brasil. Ministério Público Federal. (2004). O acesso de estudantes com deficiência às escolas e classes comuns da rede regular de ensino. Fundação Procurador Pedro Jorge de Melo e Silva. ( $2^{\mathrm{a}}$ ed.) ver. e atualiz. Brasília: Procuradoria Federal dos Direitos do Cidadão. https://media.campanha.org.br/semanadeacaomundial/2008/materiais/SAM_2008_cartilha_acesso_alunos_com_deficiencia.pdf

Colalto, C. A., Goffi-Gomez, M. V. S., Magalhães, A. T. M., Samuel, P. A., Hoshino, A. C. H., Porto, B. L., \& Tsuji, R. K. (2017). Vocabulário expressivo em crianças usuárias de implante $\quad$ coclear. $\quad$ Revista https://www.scielo.br/j/rcefac/a/YkvyQQRbNkDMmBSpJ9vKmFb/?format=pdf\&lang=pt

Costa, M. P. R., \& Barbosa, R. S. (2017). Aritmética para criança com implante coclear. Journal of Research in Special Educational Needs, 16(1), 159-163. https://doi.org/10.1111/1471-3802.12265

Frota, M. A., Amaral, L. C. G., Nobre, C. S., \& Barbosa, P. M. E. (2010). Promoção da saúde de famílias de crianças surdas. Revista Brasileira em Promoção da Saúde, 25(2), 70-75. https://doi.org/10.5020/2246

Gerhardt, T. E., \& Silveira, D. T. (2009). Métodos de Pesquisa: Editora da UFRGS.

Guerra, C. S., et al. (2015). Do sonho a realidade: vivência de mães de filhos com deficiência. Texto Contexto Enferm. 24 (2), 459-66. https://doi.org/10.1590/0104-07072015000992014

Martins, M. R., Aguiar, S. C., \& Carrapato, J. F. L. (2013). Inclusão escolar da criança com implante coclear. RIPE - Revista do Instituto de Pesquisas e Estudos: Construindo o Serviço Social, 17(32), 01-65.

Minayo, M. C. S. (2012). Análise qualitativa: teoria, passos e fidedignidade. Ciência \& Saúde Coletiva, 17(3), 621-626. https://doi.org/10.1590/S141381232012000300007

Muylaert, C. J., Sarubbi Jr, V., Gallo, P. R., Rolim Neto, M. L., \& Reis, A. O. A. (2014) Entrevistas narrativas: um importante recurso em pesquisa qualitativa. Revista da Escola de Enfermagem da USP, 48(2), 193-199. https://www.scielo.br/j/reeusp/a/NyXVhmXbg96xZNPWt9vQYCt/?lang=pt\&format=pdf

Nascimento, G. B., Schiling, N. O., Ubal, S. R., Biaggio, E. P. V., \& Kessler, T. M. (2016). Classificação socioeconômica e qualidade de vida de familiares de crianças e adolescentes com deficiência auditiva. Revista CEFAC, 18(3), 657-666. https://doi.org/10.1590/1982-0216201618313215

Rodrigues, G. R. I., Loiola-Barreiro, C. M., Pereira, T., \& Pomílio, M. C. A. (2015). A triagem auditiva neonatal antecipa o diagnóstico e a intervenção em crianças com perda auditiva? Audiology - Communication Research, 20(3), 246-254. https://doi.org/10.1590/S2317-64312015000200001453

Silva, E. V. N. (2016). Perceber, pensar e falar: o implante coclear na realidade escolar. (Dissertação de Mestrado em Educação) - Faculdade de Educação, Universidade Federal do Rio de Janeiro - UFRJ, Rio de Janeiro, RJ, Brasil. p. 137.

Souza, F. C. (2013). Usuários de implante coclear inseridos no ensino fundamental regular: percepção de pais e profissionais. (Dissertação de Mestrado em Saúde, Interdisciplinaridade e Reabilitação) - Faculdade de Ciências Médicas, Universidade Estadual de Campinas - UNICAMP, Campinas, SP, Brasil. p. 65.

Vygotski, L. S. (1997a). La defectologia y la teoría del desrrollo y la educación del niño anormal. In: Vygotski, L. S. Obras escogidas - Tomo V. Madrid: Visor Dis. Texto original de 1934.

Vygotski, L.S . (1997b). Los problemas fundamentales de la defectologia contemporânea. In: Vygotski, L. S. Obras escogidas - Tomo V. Madrid: Visor Dis. Texto original de 1929.

Vygotski, L. S. (1999). A tragédia de Hamlet, príncipe da Dinamarca. São Paulo: Martins Fontes. Texto original de 1916. 
Research, Society and Development, v. 10, n. 13, e530101321425, 2021

(CC BY 4.0) | ISSN 2525-3409 | DOI: http://dx.doi.org/10.33448/rsd-v10i13.21425

Vygotski, L. S. (2012). El problema de la edad. In: Vygotski, L. S. Obras escogidas - Tomo IV. Madrid: Machado Grupo de Distribuição S. L. Texto original de 1932 .

Yamanada, M. O. (2012). A trajetória da infância à adolescência com implante coclear: vivência de mães (Tese de Doutorado em Ciências) - Faculdade de Filosofia, Ciências e Letras de Ribeirão Preto, Universidade de São Paulo - USP, Ribeirão Preto, SP, Brasil. p. 224.

Yamanaka, D. A. R., Silva, R. B. P., Zanolli, M. L., \& Silva, A. B. P. (2010). Implante coclear em crianças: a visão dos pais. Psicologia teoria e pesquisa, 26(3), 465-473. https://doi.org/10.1590/S0102-37722010000300009 